\title{
In vitro analysis of the anticancer properties of scorpion venom in colorectal and breast cancer cell lines
}

\author{
ABDULRAHMAN KHAZIM AL-ASMARI ${ }^{1}$, MOZAFFARUL ISLAM ${ }^{1}$ and ALI MATER AL-ZAHRANI ${ }^{2}$ \\ ${ }^{1}$ Research Center; ${ }^{2}$ Department of Oncology, Prince Sultan Military Medical City Hospital, \\ Riyadh 11159, Kingdom of Saudi Arabia
}

Received January 22, 2015; Accepted November 18, 2015

DOI: 10.3892/ol.2015.4036

\begin{abstract}
Scorpion venom contains various types of proteins and peptides that are able to act as inhibitors of neurotransmitter molecules. This is achieved primarily via the inhibition of ion channels. In addition, scorpion venom has been demonstrated to exhibit anticancer properties in prostate and breast cancer, as well as leukemia. The anticancer properties of scorpion venom are due to its inhibitory effect on matrix metalloproteinase (MMP) activity, which leads to reduced motility and invasion in tumor cells. The inhibitory effects of venom on MMPs additionally lead to a reduction in the metastatic potential of malignant tumors. In the present study, the effect of venom obtained from a local serpentarium facility was examined in colorectal and breast cancer cell lines. Cell motility and clonogenic survival assays revealed a significant decrease (60-90\%) in cell motility and colony formation, two significant hallmarks of cancer survival, following treatment with various concentrations of venom. These results were in agreement with previous studies demonstrating the anticancer activity of scorpion venom. In conclusion, the venom utilized at the Research Center of Prince Sultan Military Medical City Hospital (Riyadh, Saudi Arabia) possesses significant anticancer potential against colorectal and breast cancer cell lines.
\end{abstract}

\section{Introduction}

Scorpion stings are a major health hazard worldwide, and in the Saudi Arabian population in particular (1). High rates of incidence of scorpion stings have been reported in Northwestern regions of Saudi Arabia (2,3). Approximately 1,500 species of scorpion have been reported so far, including one of the oldest species on earth (4). As reported, the incidence of scorpion

Correspondence to: Dr Abdulrahman Khazim Al-Asmari, Research Center, Prince Sultan Military Medical City Hospital, Makkah Al Mukarramah Branch Road, Riyadh 11159, Kingdom of Saudi Arabia

E-mail: abdulrahman.alasmari@gmail.com

Key words: colorectal cancer, breast cancer, cell motility, colony formation, matrix metalloproteinases stings between the years of 1993-1997 was 72,168 individuals. Of these, 25 species of scorpion exhibiting high toxicity have been identified in Saudi Arabia (5). The climatic, socioeconomic and cultural circumstances of Saudi Arabia further promote the occurrence of scorpion stings in the local inhabitants. There are an estimated 14,500 cases/year of scorpion stings in the different regions of Saudi Arabia (6). The venom from the Androctonus genus, which is commonly observed in Saudi Arabia, is considered to be the most toxic type of scorpion venom, compared with the venom of other species (7).

The sting and envenomation of the scorpion generates discomfort and pain in the victims, and may develop into a number of medical complications, including hypotension, cardiac arrhythmia and respiratory distress (8). The mechanism underlying scorpion stings and their associated health complications is due to the venom acting as a potent neurotoxin, which causes the inhibition of the $\mathrm{Na}^{+} / \mathrm{K}^{+}$-ATPase pump, thus paralyzing the sympathetic and parasympathetic nervous systems, with severe-to-fatal consequences (9).

Biochemically, scorpion venom contains several basic proteins that are responsible for its neurotoxicity (10). Amino acid sequencing of venom obtained from different species of scorpion revealed that the above neurotoxins consist of 60-70 amino acid residues, which are cross-linked by four disulfide bridges (10). Furthermore, due to the close similarities in their amino acid composition, all scorpion toxins possess similar three-dimensional structures (10). In spite of the various negative effects of scorpion envenomation, scorpion venom contains numerous beneficial components, which are currently being utilized for drug design in the pharmaceutical industry $(11,12)$. A number of antibacterial, antifungal (yeast) and antiviral substances have been derived from peptides isolated from scorpion venom $(13,14)$. Additionally, scorpion venom has demonstrated anticancer potential in pancreatic cancer (15) and leukemia (16). Scorpion venom is constituted by a complex mixture of salts, nucleotides, biogenic amines, peptides, enzymes, mucoproteins and other proteins such as neurotoxins (17). It has been recently observed that animal venoms and toxins possess anticancer potential. Previous studies have revealed that scorpion venoms and toxins are able to reduce cancer growth, induce apoptosis and inhibit progression and metastasis in vivo and in vitro (17). A number of active molecules with anticancer properties, including induction of cell cycle arrest and apoptosis, inhibition of proliferation and 
reduction of cell migration and invasion, have been isolated from scorpion venom (17). These observations have provided insight into the application of scorpion venom and toxins as possible novel anticancer therapeutics (17).

Cancer or malignancy may be defined as the uncontrolled growth of cells leading to the development of disease. The most remarkable feature of cancerous cells is their capacity to invade and metastasize to different regions of the body and form secondary tumors in these organs. The current study analyzed the effects of scorpion venom on cancer cells. In particular, of phenotypic alterations such as variations in cell motility and clonogenic survival were assessed using an anchorage-dependent colony formation assay. A total of three distinct cancer cell lines derived from colorectal (HCT-8 and HCT-116) and breast (MDA-MB-231) cancer were selected for the present study. The rationale behind selecting the above cell lines was the ease of availability of these cells at the Research Center of Prince Sultan Military Medical City Hospital (Riyadh, Saudi Arabia) and the prevalence of these two malignancies among the Saudi Arabian population.

Colorectal cancer is cancer of the colon or rectum, which is part of the large intestine or gastrointestinal system. Colon cancer is the third most fatal type of cancer worldwide among men and women. In 2014, it was estimated that $\sim 138,000$ patients were diagnosed with colorectal cancer in USA, of which, $50 \%$ succumbed to disease (18). Similarly, breast cancer is the second cause of cancer-associated mortality worldwide among women (19). As reported by the National Saudi Cancer Registry (Riyadh, Saudi Arabia), a case study conducted between 2001 and 2006 identified a significant increase in the occurrence of colorectal cancer among the Saudi Arabian population (20). A similar study conducted by Alghamdi et al (21) between 2001 and 2008 reported a significant increase in female breast cancer, particularly among young women, in Saudi Arabia. The above study also specified the geographical locations of the prevailing disease, and identified that the Eastern region of Saudi Arabia presented a linear upward trend in the occurrence of breast cancer, compared with Southern areas of the country, including Jazan, Baha and Najran (21).

Cell invasion, migration and metastasis to different parts of the body are the most important characteristic features of cancer cells. The migration of cancerous cells depends on the tumor microenvironment, from which the cells receive nourishment and support for the formation of novel vasculature (angiogenesis), which enables them to spread (22). The degradation of the extracellular matrix (ECM) facilitates the movement of cancer cells in the body (23). Cancerous tumors are comprised of aberrant cells in addition to macromolecules from the ECM, which constitute a substantial part of their volume. These macromolecules are predominantly polysaccharides and proteins of various types that are secreted locally, which are arranged in a mesh-like structure and are closely associated with the malignant tumor. Previous studies have revealed the role of matrix metalloproteinases (MMPs) in the distortion of the ECM meshwork, which results in the generation of a free passage for cancer cells to migrate and invade distal parts of the body, thus leading to the progression of metastatic disease $(24,25)$. MMPs are zinc-dependent endopeptidases that belong to the metzincin enzyme superfamily and may adversely affect the architecture of the ECM network (26-28).
Recent studies have demonstrated that a 36-amino acid peptide sequence, which contains four disulfide bridges and derives from scorpion venom, is effective in inhibiting the action of various MMPs in glioblastoma (29-31), pancreatic (15) and breast cancer (32). However, there are limited studies on the effect of scorpion venom as an anticancer agent on colorectal cancer. In those previous studies, MMPs were observed to be constitutively overexpressed (33). Therefore, the aim of the present study was to investigate the anticancer potential of the scorpion venom obtained at the Research Center of Prince Sultan Military Medical City Hospital, against colorectal and breast cancer cell lines.

The findings of the present study indicated that reduced cell motility and colony formation correlated with the inhibitory role of scorpion venom on colorectal and breast cancer cell lines. Furthermore, these results suggested that venom therapy may constitute an important step towards the development of a more specific treatment for aggressive types of cancer. To the best of our knowledge, the present study is the first to demonstrate the phenotypic changes that occur in colorectal and breast cancer cell lines following treatment with scorpion venom.

\section{Materials and methods}

Scorpions and venom collection. Medically important species of scorpion, including Androctonus crassicauda, Androctonus bicolor and Leiurus quinquestriatus, were collected from various regions of Saudi Arabia and housed at Prince Sultan Military Medical City Hospital (Riyadh, Saudi Arabia). A male and a female scorpion were housed in a plastic box and fed with mealworms and water ad libitum. Temperature of the room kept at $25^{\circ} \mathrm{C}$ with $12 \mathrm{~h}$ light and dark cycles. The Research Ethics Committee of Prince Sultan Military Medical City Hospital approved the present study (project no. 1a/2013). Scorpion venom was milked by electrical stimulation using 6012 Dual Pulse Stimulator (Harvard Apparatus, Holliston, MA, USA). The ejected venom was collected in glass beakers and immediately stored at $-20^{\circ} \mathrm{C}$. The recovery of venom was achieved by mixing the sample with distilled water, followed by centrifugation at $199 \mathrm{x} g$ for $10 \mathrm{~min}$. The supernatant was then lyophilized and stored at $-80^{\circ} \mathrm{C}$ until required. A stock solution of venom at a concentration of $10 \mathrm{mg} / \mathrm{ml}$ was prepared in phosphate-buffered saline (PBS), which was sterilized by passage through a $0.22-\mu \mathrm{m}$ membrane filter (Cat no. SLGN 033RS, Thomas Scientific, Swedesboro, NJ, USA) prior to use. Additional dilution, as per the experimental requirements, was performed using an identical buffer system. For simplicity, venoms were designated as venom-1, -2 and -3 , which were obtained from the scorpion species Androctonus crassicauda, Androctonus bicolor and Leiurus quinquestriatus, respectively.

Cell culture. Cancer cell lines, namely HCT-8 [derived from ileocecal adenocarcinoma of a 67-year-old male patient (34)], HCT-116 [derived from colorectal carcinoma of a male patient (35)] and MDA-MB-231 [obtained from breast carcinoma (36)], were supplied by the Cancer Research Facility of King Fahad National Guard Hospital (Riyadh, Saudi Arabia). The cell lines HCT- 8 and HCT-116 were cultured in RPMI-1640 medium, while MDA-MB-231 cells were 
A

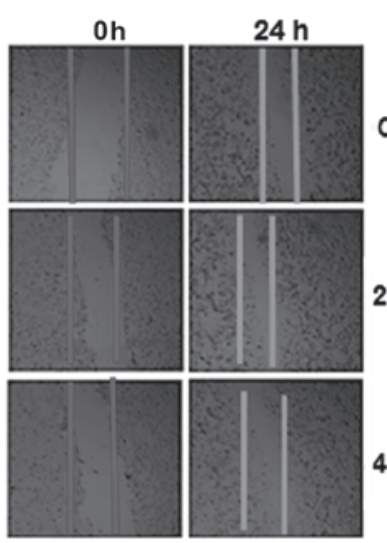

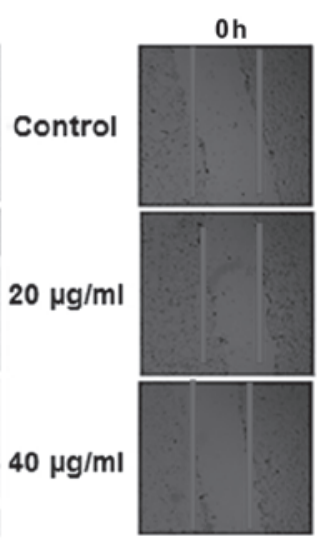

Oh

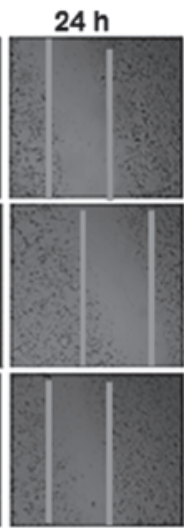

B

$60 \mu \mathrm{g} / \mathrm{ml}$

$80 \mu \mathrm{g} / \mathrm{ml}$

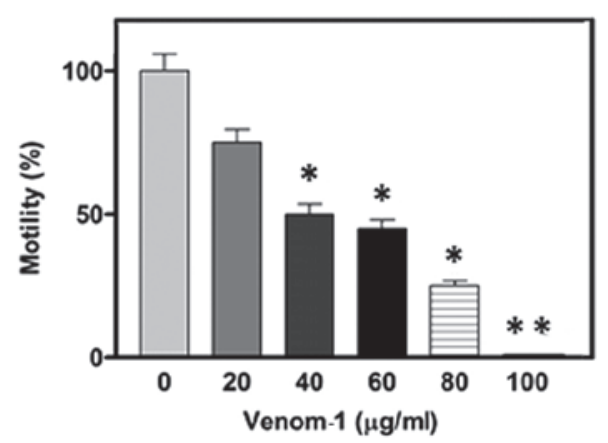

D

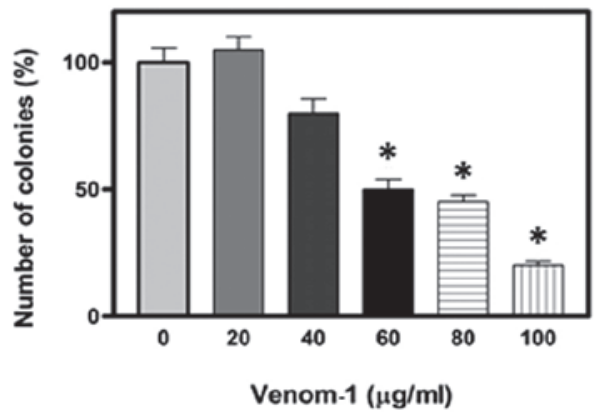

$100 \mu \mathrm{g} / \mathrm{ml}$
C

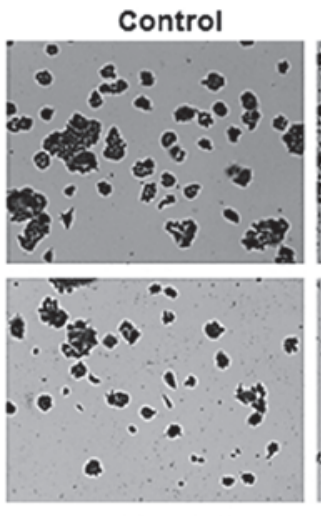

$60 \mu \mathrm{g} / \mathrm{ml}$

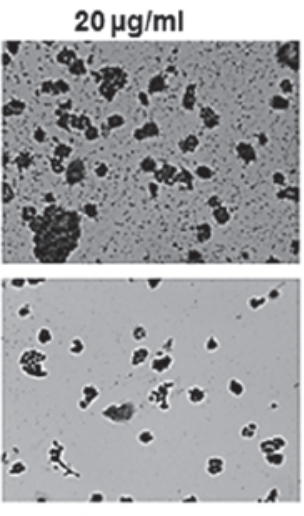

$80 \mu \mathrm{g} / \mathrm{ml}$

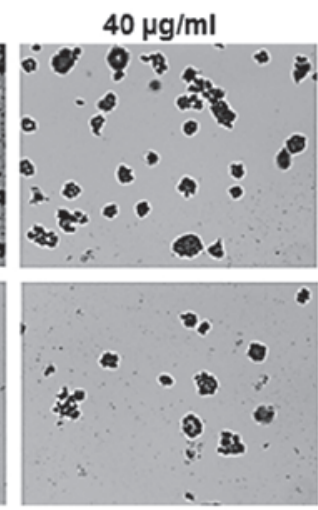

$100 \mu \mathrm{g} / \mathrm{ml}$

Figure 1. Representative images of cell motility and colony formation in HCT-8 cells following treatment with venom-1. (A) Cell motility was significantly reduced in HCT- 8 cells following venom-1 treatment. (B) A decrease in cell motility of $25-100 \%$ was observed in HCT- 8 cells treated with venom-1. Data are presented as the mean \pm standard deviation of three independent experiments. (C) Colony formation was significantly reduced in HCT-8 cells following venom-1 treatment. (D) A $78 \%$ decrease in colony formation was detected upon venom-1 treatment. Data are presented as the mean \pm standard deviation of the count of five independent colonies per high-power field. ${ }^{*} \mathrm{P}<0.05$ vs. control. ${ }^{* *} \mathrm{P}<0.01$ vs. control.

cultured in Dulbecco's Modified Eagle's medium (Life Technologies, Thermo Fisher Scientific, Inc., Waltham, MA, USA) containing $10 \%$ heat-inactivated fetal bovine serum (PAA Laboratories, GE Healthcare Life Sciences, Chalfont, UK), supplemented with $2 \mathrm{mM}$ L-glutamine (cat no. 25030-081), $50 \mu \mathrm{g} / \mathrm{ml}$ penicillin $\mathrm{G}$ and $50 \mu \mathrm{g} / \mathrm{ml}$ streptomycin sulfate (cat no. 10378-016; all Life Technologies, Thermo Fisher Scientific, Inc.). This combination was designated as complete medium. The cultures were maintained by replacing the medium on alternate days until cells reached the desired confluence. In order to initiate subcultures, 80-90\% confluent cells were washed using $\mathrm{Ca}^{2+}$ and $\mathrm{Mg}^{2+}$-free warm PBS, prior to be treated with $\sim 3 \mathrm{ml}$ trypsin-ethylenediaminetetraacetic acid (EDTA) solution (0.05\% trypsin and $0.53 \mathrm{mM}$ EDTA; cat no. 25200-056; Life technologies, Thermo Fisher Scientific, Inc.) for $5 \mathrm{~min}$ at $37^{\circ} \mathrm{C}$. Subsequently, $5 \mathrm{ml}$ complete medium was added to the cells to quench the effect of trypsin, and the cell suspension was next centrifuged at 1,000 rpm for $5 \mathrm{~min}$. The pelleted cells were resuspended in complete medium and seeded into $25^{\circ} \mathrm{cm}^{2}$ culture flasks at a density of $1 \times 10^{4}$ cells $/ \mathrm{cm}^{2}$. The cultures were maintained in a humidified atmosphere at $37^{\circ} \mathrm{C}$ with $5 \% \mathrm{CO}_{2}$ and $95 \% \mathrm{O}_{2}$.

Cell motility assay. Cell motility assays were performed in 6-well cell culture plates. HCT-8 and MDA-MB-231 cells at $\sim 80 \%$ confluence were washed using PBS, and a fine scratch in the form of a groove was created in the cell monolayer using a sterile pipette tip, and immediately photographed. This time point was designated as $0 \mathrm{~h}$. Subsequently, cells were supplemented with complete medium and allowed to grow in the presence of various concentrations $(20,40,60,80$ and $100 \mu \mathrm{g} / \mathrm{ml})$ of scorpion venom -1, which was obtained from Androctonus crassicauda. Next HCT-116 cells were treated with 50 and $100 \mu \mathrm{g} / \mathrm{ml}$ scorpion venom -1 . Additionally, cell motility and colony formation in MDA-MB-231 cells were examined following treatment with 50 and $100 \mu \mathrm{g} / \mathrm{ml}$ of venoms -2 and -3 , obtained from the species of Androctonus bicolor and Leiurus quinquestriatus, respectively. Control cells were grown in the absence of venom, and treated with equivalent volumes of PBS instead.

The migration of cells from the edge of the scratch towards the center was monitored microscopically at magnification x10 upon $24 \mathrm{~h}$ of incubation, in order to assess the extent of the scratched area that had been covered by the migrated cells. The width of the scratch was measured at 0 and $24 \mathrm{~h}$ to calculate the percentage of the gap covered by the cells in a 24 -h time period.

Clonogenic survival assay. The clonogenic survival assay was performed according to the protocol previously described by Franken et al (37). Briefly, 500 cells were cultured in 6-well 
A
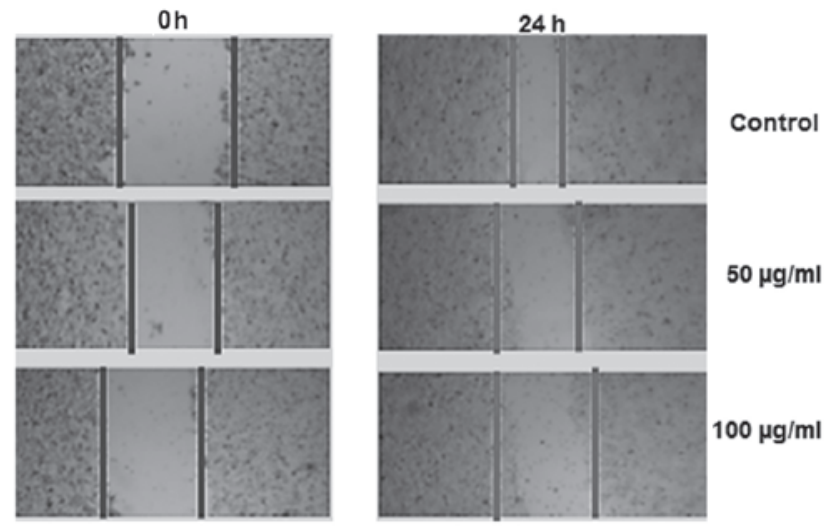

C
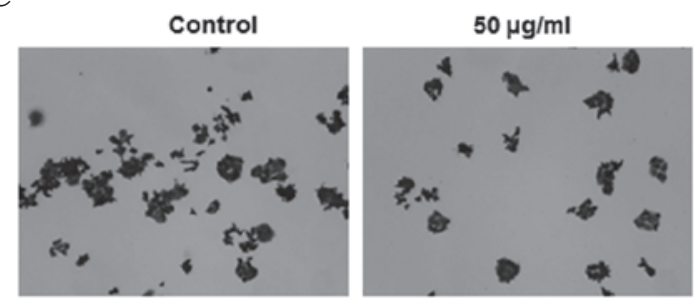

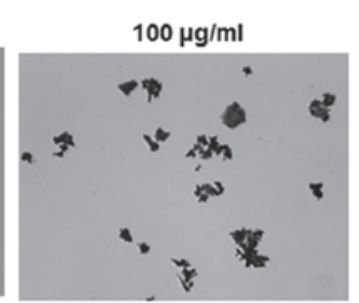

B

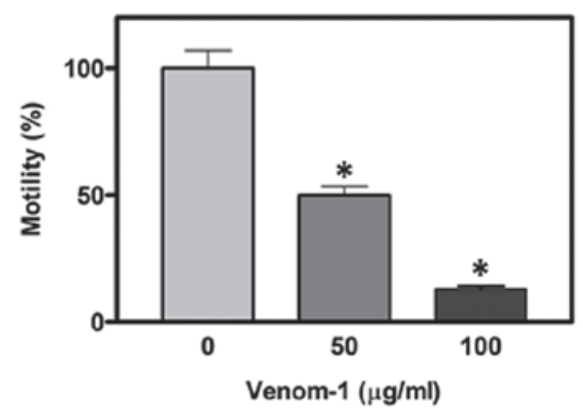

D

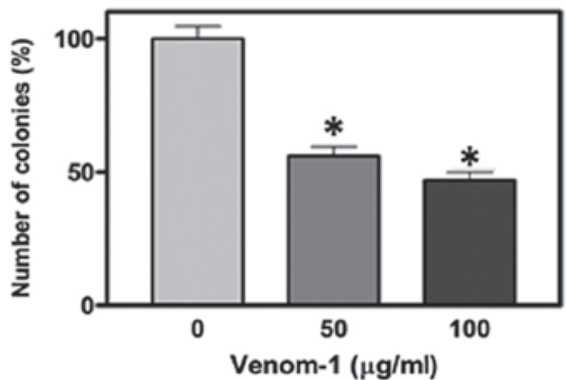

Figure 2. Representative images of cell motility and colony formation in HCT-116 cells following treatment with venom-1. (A) Cell motility was significantly reduced in HCT-116 cells following venom-1 treatment. (B) A 50-80\% decrease in cell motility was observed in HCT-116 cells treated with venom-1. Data are presented as the mean \pm standard deviation of three independent experiments. (C) Colony formation was significantly reduced in HCT-116 cells following venom-1 treatment. (D) A 58\% decrease in colony formation was detected upon venom-1 treatment. Data are presented as the mean \pm standard deviation of the count of five independent colonies per high-power field. ${ }^{*} \mathrm{P}<0.05$ vs. control.

A

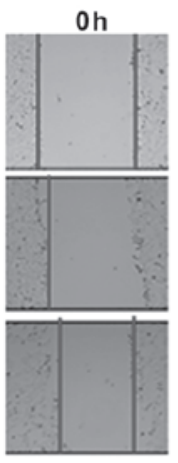

$24 \mathrm{~h}$
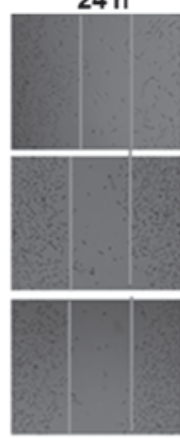

$20 \mu \mathrm{g} / \mathrm{ml}$

$40 \mu \mathrm{g} / \mathrm{ml}$

C
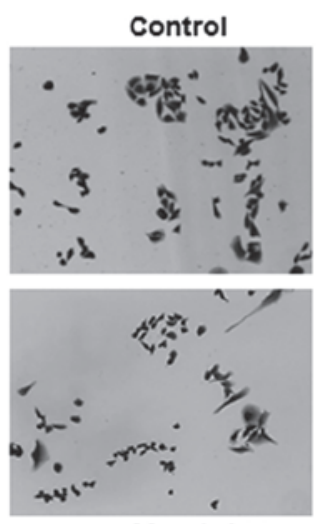

$60 \mu \mathrm{g} / \mathrm{ml}$
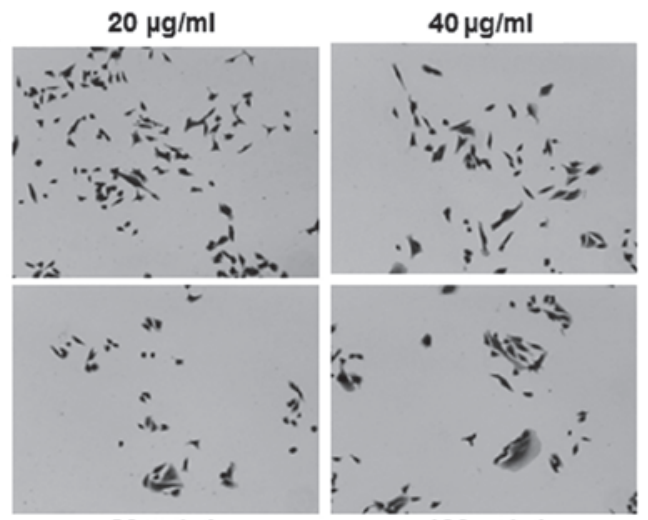

$80 \mu \mathrm{g} / \mathrm{ml}$

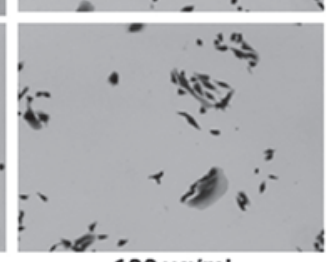

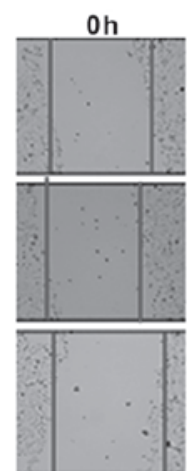

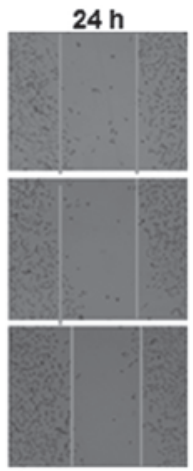

$60 \mu \mathrm{g} / \mathrm{m}$

$80 \mu \mathrm{g} / \mathrm{ml}$

$100 \mu \mathrm{g} / \mathrm{ml}$
B

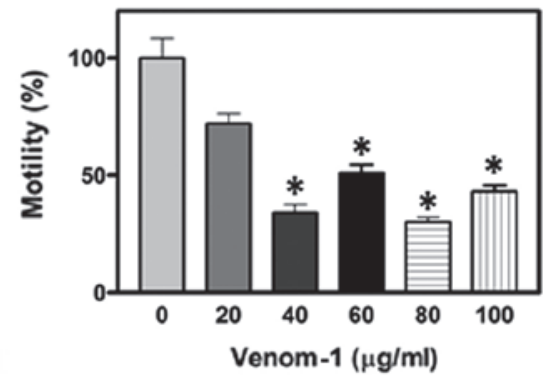

D

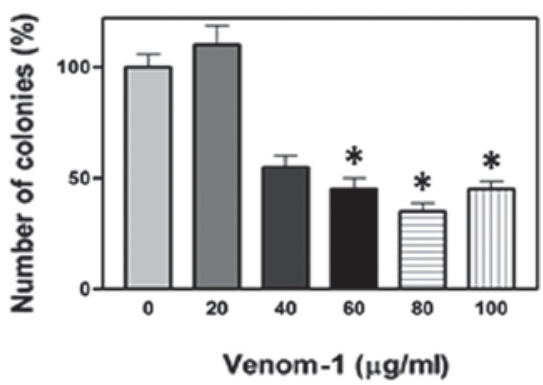

Figure 3. Representative images of cell motility and colony formation in MDA-MB-231 cells following treatment with venom-1. (A) Cell motility was significantly reduced in MDA-MB-231 cells following venom-1 treatment. (B) A 67-72\% decrease in cell motility was observed. Data are presented as the mean \pm standard deviation of three independent experiments. (C) Colony formation was significantly reduced in MDA-MB-231 cells following venom-1 treatment. (D) A 50-70\% decrease in colony formation was detected upon venom-1 treatment. Data are presented as the mean \pm standard deviation of the count of five independent colonies per high-power field. "P<0.05 vs. control. 
A
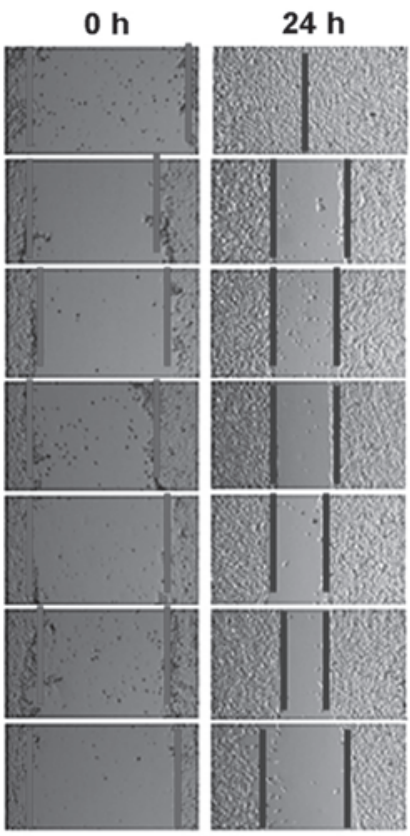

Control

V1-50 $\mu \mathrm{g} / \mathrm{ml}$

$\mathrm{V} 1-100 \mu \mathrm{g} / \mathrm{ml}$

V2-50 $\mu \mathrm{g} / \mathrm{ml}$

$\mathrm{V} 2-100 \mu \mathrm{g} / \mathrm{ml}$

$\mathrm{V} 3-50 \mu \mathrm{g} / \mathrm{ml}$

$\mathrm{V} 3-100 \mu \mathrm{g} / \mathrm{ml}$
B

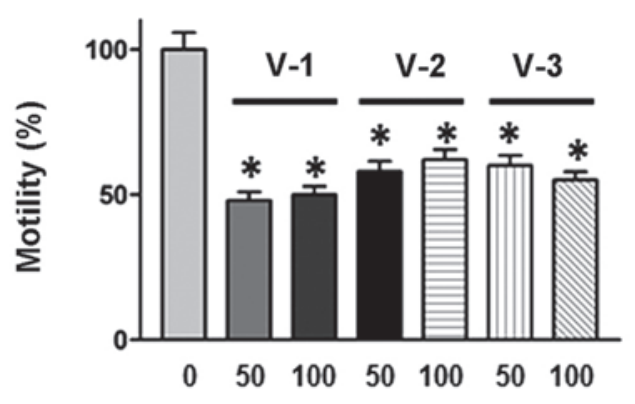

D

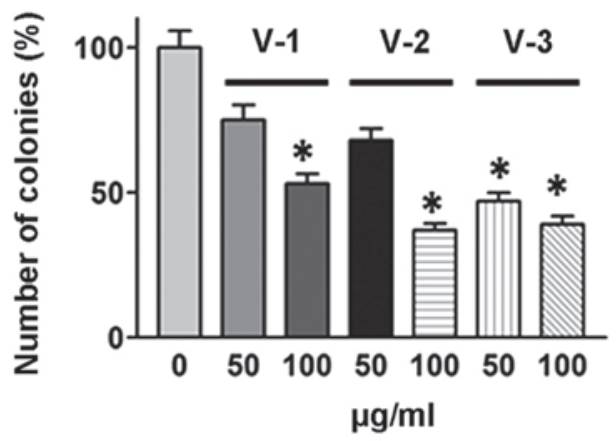

Figure 4. Representative images of cell motility and colony formation in MDA-MB-231 cells following treatment with various venoms. (A) Cell motility was significantly reduced in MDA-MB-231 cells following treatment with V-1, V-2 and V-3. (B) A 50-63\% decrease in cell motility was observed in MDA-MB-231 cells treated with V-1, V-2 and V-3. Data are presented as the mean \pm standard deviation of three independent experiments. (C) Colony formation was significantly reduced in MDA-MB-231 cells following treatment with V-1, V-2 and V-3. (D) A 40-75\% decrease in colony formation was detected upon treatment with all three venoms. Data are presented as the mean \pm standard deviation of the count of five independent colonies per high-power field. ${ }^{*} \mathrm{P}<0.05$ vs. control. V, venom.

plates for 2 weeks, in the absence or presence of various concentrations $(20,40,60,80$ and $100 \mu \mathrm{g} / \mathrm{ml})$ of scorpion venom -1 . HCT-116 cells were treated with 50 and $100 \mu \mathrm{g} /$ $\mathrm{ml}$ scorpion venom -1. Additionally, MDA-MB-231 cells were examined following treatment with 50 and $100 \mu \mathrm{g} / \mathrm{ml}$ of venoms -2 and -3 , respectively. Control cells were grown in the absence of venom, and treated with equivalent volumes of PBS instead. Upon termination of the assay, the cells were washed with PBS, and the colonies formed were subsequently stained for $45 \mathrm{~min}$ with $0.5 \%$ (w/v) crystal violet (cat no. C 3886; Sigma-Aldrich, St. Louis, MO, USA) prepared in 0.6\% (v/v) glutaraldehyde solution (cat no. C 3886; Sigma-Aldrich), rinsed with water and air-dried.
Statistical analysis. Statistical analyses were performed using the Student's $t$-test. Results are presented as the mean \pm standard deviation. The data were analyzed in triplicate, using Graph Pad Prism software, version 4.0 (Graph Pad Software, Inc., San Diego, CA, USA). P $<0.05$ was considered to indicate a statistically significant difference.

\section{Results}

Treatment with scorpion venom decreases motility and colony formation in HCT-8 cells. The present study focused on the in vitro effects of scorpion venom in three distinct well-established cancer cell lines, namely HCT-8, HCT-116 and 
MDA-MB-231. These cell lines have been well-characterized, and are widely used as models to investigate various aspects of cancer metastasis. The main aim of the present study was to evaluate the anticancerous potential of venom obtained from scorpions. As demonstrated in Fig. 1A, the cell motility of the HCT- 8 cell line was observed to decrease in a dose-dependent manner. Notably, at a concentration of $100 \mu \mathrm{g} / \mathrm{ml}$ of venom-1, a complete halt in cell motility was observed following $24 \mathrm{~h}$ of incubation. Fig. 1B reveals the gradual percentage of scratch covered in the HCT- 8 cell line $24 \mathrm{~h}$ subsequent to wounding. In addition, anchorage-dependent colony formation, a hallmark of cancer cell survival, was examined. A marked decrease in colony formation was observed following venom-1 treatment in the HCT-8 cell line, compared with the control (Fig. 1C). Fig. 1D reveals a $\sim 70-90 \%$ reduction in colony formation at a concentration of $80-100 \mu \mathrm{g} / \mathrm{ml}$ of venom-1.

Treatment with scorpion venom decreases motility and colony formation in HCT-116 cells. In HCT-116 cells, a significant reduction in cell motility and colony formation was observed following treatment with 50 and $100 \mu \mathrm{g} / \mathrm{ml}$ venom-1 (Fig. 2A and C). Statistical analysis of cell motility and colony formation is depicted in the form of bar graphs (Fig. 2B and D). Asterisks indicate the significance of cell motility and colony formation in the treatment group, compared with the control $(\mathrm{P}<0.05)$.

Treatment with scorpion venom decreases motility and colony formation in MDA-MB-231 cells. In order to investigate the efficacy of venom-1 as an anticancer agent in different types of cancer other than colorectal, a breast cancer cell line, namely MDA-MB-231, was also included in the present study. A similar pattern of inhibition in cell motility and colony formation was observed (Fig. 3), confirming that the action of venom-1 was not restricted to one type of cell line, but may display a wide range of anticancer properties, as evidenced by the phenotypic changes observed in the cell lines analyzed in the present study. Furthermore, venom obtained from Androctonus bicolor and Leiurus quinquestriatus was used against the MDA-MB-231 cell line, and a similar inhibitory effect was observed on colony formation and cell motility (Fig. 4). These findings suggest a potential novel area of research aimed to elucidate the molecular mechanism responsible for the anticancer activities of scorpion venom.

\section{Discussion}

Scorpion venom is a chemically enriched substance, containing various proteins and peptides, which may act as an anticancer agent. Scorpion venom exhibits anticancer potential via the inhibition of cell proliferation and growth in vitro by interfering with the activity of various signaling molecules such as phosphatase and tensin homolog, which are involved in a number of signal transduction cascades (38-40). The present study evaluated the effects of scorpion venom on cell motility and colony formation in two well-established and characterized colorectal cancer cell lines, HCT-8 and HCT-116, in addition to the breast cancer cell line MDA-MB-231. A marked reduction in cell motility and colony formation was observed in a dose-dependent manner in the above colorectal cancer cell lines. Due to the limited availability of venom, the median concentration of venom-1 that was used to treat HCT-8 cells was selected to evaluate the effects of venom- 1 in the HCT-116 cell line, and the same inhibitory effect was observed in cell motility and anchorage-dependent colony formation assays. In order to investigate whether scorpion venom exhibited a broad range of anticancer activity rather than being specific only for colorectal cancer cells, a breast cancer cell line, namely MDA-MB-231, was additionally studied. A perceptive decrease in cell motility and colony formation was also observed in these cell line, although within minor experimental variation, indicating that venom- 1 also exhibited an inhibitory effect on breast cancer cells. Minor fluctuations in the outcome of the treatments may be attributed to the differential uptake of venom-1 in the different experimental setups. Nevertheless, the results demonstrated that venom-1 acted as an inhibitor of cancer cell motility. Furthermore, a similar phenotypic inhibitory effect was observed following treatment with venoms obtained from Androctonus bicolor (venom-2) and Leiurus quinquestriatus (venom-3). Cell motility and colony formation are two important factors that are widely used in cancer research to evaluate the effectiveness of anticancer drugs or micro-RNAs on cancer progression $(41,42)$. Focal adhesion kinase (FAK) is an important molecule for focal assembly and contraction of cells, which facilitates movement and invasion into the ECM. The activation of FAK is necessary to achieve adhesion, followed by movement of cells in various directions and enhancement of cell motility (43). Reduced cell motility in the presence of scorpion venom, as demonstrated in the present study, may be a manifestation of loss of active FAK due to the action of the venom, which may instigate a signaling cascade leading to phenotypic changes via the retardation of normal cell activities. Similarly, clonogenic assay is a representation of cell proliferation, and assesses the survival of a single cell, which may form colonies to ensure its growth and survival (37). As presented in the current study, a marked decrease in colony formation following treatment with venom was an additional indication of the inhibition of cancer cell proliferation in the presence of the three scorpion venoms analyzed.

The findings of the present study suggest the identification of a novel and productive area of future research aimed to elucidate the underlying molecular mechanism that enables scorpion venom to inhibit cell motility and colony formation in cancer cell lines. Two possible mechanisms may be proposed to explain this reduction in cell motility and colony formation: i) A decrease in the expression of MMPs, and ii) a reduction in the phosphorylation levels of FAK, which is involved in cell migration and invasion. However, these hypothetical mechanisms will require future investigation.

In conclusion, the present study demonstrated that scorpion venom is able to act as an anticancer agent by decreasing cell motility and colony formation in colorectal and breast cancer cell lines. The results of the present study add to the increasing body of evidence supporting the potential of scorpion venom to be used as an anticancer agent, and indicate the requirement for molecular analysis of the action of the underlying signaling mechanisms. Therefore, scorpion venom may represent a valuable therapeutic tool to be used as part of the therapeutic regimen for the treatment of patients with colorectal and breast cancer. 


\section{Acknowledgments}

The authors would like to thank the Research Center of Prince Sultan Military Medical City Hospital and King Abdulaziz City for Science and Technology (KACST) for providing the necessary facilities and financial support. The authors would also like to thank Dr Bandar Al-Knawy, Director of the Research Center of King Saud Bin Abdulaziz Medical City Hospital (Riyadh, Saudi Arabia) for providing the colorectal and breast cancer cell lines used in the present study.

\section{References}

1. Al-Asmari AK and Al-Saif AA: Scorpion sting syndrome in a general hospital in Saudi Arabia. Saudi Med J 25: 64-70, 2004.

2. Mahaba HM and El Sayed SA: Scorpion sting: Is it a health problem in Saudi Arabia? Evaluation of management of 820 cases. Saudi Med J 17: 15-21, 1996.

3. Mahaba HM: Scorpion sting syndrome: Epidemiology, clinical presentations and management of 2240 cases. East Mediterr Health J 3: 82-89, 1997.

4. Simard MJ and Watt DD: Venoms and toxins. In: The Biology of Scorpions. Polis GA (ed). Vol X. Yth edition. Stanford University Press, Redwood City, CA, pp414-444, 1990.

5. Al Asmari AK, Khan HA, Manthiri RA, Al Yahya KM and Al Otaibi KE: Effects of Echis pyramidum snake venom on hepatic and renal antioxidant enzymes and lipid peroxidation in rats. J Biochem Mol Toxicol 28: 407-412, 2014.

6. Al Asmari AK, AlZahrani AG, Al Jowhary S and Arshaduddin M: Clinical aspects and frequency of scorpion stings in the Riyadh region of Saudi Arabia. Saudi Med J 33: 852-858, 2012.

7. Ozkan O and Filazi A: The determination of acute lethal dose-50 (LD50) levels of venom in mice, obtained by different methods from scorpions, Androctonus crassicauda (Oliver 1807). Turkiye Parazitol Derg 28: 50-53, 2004.

8. Bawaskar HS and Bawaskar PH: Scorpion sting: Update. J Assoc Physicians India 60: 46-55, 2012.

9. Petricevich VL: Effect of Tityus serrulatus venom on cytokine production and the activity of murine macrophages. Mediators Inflamm 11: 23-31, 2002.

10. Rochat H, Bernard P and Couraud F: Scorpion toxins: Chemistry and mode of action. In: Advances in Cytopharmacology, Neurotoxins: Tools in Neurobiology. Ceccarelli B and Clementi F (eds). Vol 3. Yth edition. Raven, New York, NY, pp325-334, 1979.

11. Andreotti N, Jouirou B, Mouhat S, Mouhat L and Sabatier JM: Therapeutic value of peptides from animal Venoms. In Amino Acids, Peptides and Proteins, Comprehensive Natural Products II Chemistry and Biology. Mander L and Lui HD (eds). Vol X. Yth edition. Elsevier, Oxford, pp287-303, 2010.

12. Ahn MY, Ryu KS, Lee YW and Kim YS: Cytotoxicity and L-amino acid oxidase activity of crude insect drugs. Arch Pharm Res 23: 477-481, 2000.

13. Zhao Z, Hong W, Zeng Z, Wu Y, Hu K, Tian X, Li W and Cao Z: Mucroporin-M1 inhibits hepatitis B virus replication by activating the mitogen-activated protein kinase (MAPK) pathway and down-regulating HNF4- $\alpha$ in vitro and in vivo. J Biol Chem 287: 30181-30190, 2012.

14. Chen Y, Cao L, Zhong M, Zhang Y, Han C, Li Q, Yang J, Zhou D, Shi W, He B, et al: Anti-HIV-1 activity of a new scorpion venom peptide derivative Kn2-7. PLoS One 7: e34947, 2012.

15. El-Ghlban S, Kasai T, Shigehiro T, Yin HX, Sekhar S, Ida M, Sanchez A, Mizutani A, Kudoh T, Murakami H and Seno M: Chlorotoxin-Fc fusion inhibits release of MMP-2 from pancreatic cancer cells. Biomed Res Int 2014: 152659, 2014.

16. Gupta SD, Gomes A, Debnath A, Saha A and Gomes A: Apoptosis induction in human leukemic cells by a novel protein Bengalin, isolated from Indian black scorpion venom: Through mitochondrial pathway and inhibition of heat shock proteins. Chem Biol Interact 183: 293-303, 2010.

17. Ding J, Chua PJ, Bay BH and Gopalakrishnakone P: Scorpion venoms as a potential source of novel cancer therapeutic compounds. Exp Biol Med (Maywood) 239: 387-393, 2014

18. Colorectal Cancer Facts \& Figures 2014-2016. American Cancer Society Inc., Atlanta, 2014.
19. Breast Cancer Facts \& Figures 2013-2014. American Cancer Society, Inc., Atlanta. 2013.

20. Mosli MH and Al-Ahwal MS: Colorectal cancer in the Kingdom of Saudi Arabia: Need for screening. Asian Pac J Cancer Prev 13: 3809-3813, 2012.

21. Alghamdi IG, Hussain II, Alghamdi MS and El-Sheemy MA: The incidence rate of female breast cancer in Saudi Arabia: An observational descriptive epidemiological analysis of data from Saudi Cancer Registry 2001-2008. Breast Cancer (Dove Med Press) 5: 103-109, 2013.

22. Folkman J: Angiogenesis: Initiation and control. Ann N Y Acad Sci 401: 212-227, 1982.

23. Liotta LA, Steeg PS and Stetler-Stevenson WG: Cancer metastasis and angiogenesis: An imbalance of positive and negative regulation. Cell 64: 327-336, 1991.

24. Sato H, Takino T, Okada Y, Cao J, Shinagawa A, Yamamoto E and Seiki M: A matrix metalloproteinase expressed on the surface of invasive tumour cells. Nature 370: 61-65, 1994.

25. Itoh Y and Seiki M: MT1-MMP: A potent modifier of pericellular microenvironment. J Cell Physiol 206: 1-8, 2006.

26. Gross J and Lapiere CM: Collagenolytic activity in amphibian tissues: A tissue culture assay. Proc Natl Acad Sci USA 48: 1014-1022, 1962

27. Gross J and Nagai Y: Specific degradation of the collagen molecule by tadpole collagenolytic enzyme. Proc Natl Acad Sci USA 54: 1197-1204, 1965.

28. Van Lint P and Libert C: Chemokine and cytokine processing by matrix metalloproteinases and its effect on leukocyte migration and inflammation. J Leukoc Biol 82: 1375-1381, 2007.

29. Deshane J, Garner CC and Sontheimer H: Chlorotoxin inhibits glioma cell invasion via matrix metalloproteinase-2. J Biol Chem 278: 4135-4144, 2003.

30. Soroceanu L, Gillespie Y, Khazaeli MB and Sontheimer H: Use of chlorotoxin for targeting of primary brain tumors. Cancer Res 58: 4871-4879, 1998.

31. Lyons SA, O'Neal J and Sontheimer H: Chlorotoxin, a scorpion-derived peptide, specifically binds to gliomas and tumors of neuroectodermal origin. Glia 39: 162-173, 2002.

32. Qin C, He B, Dai W, Zhang H, Wang X, Wang J, Zhang X, Wang G, Yin L and Zhang Q: Inhibition of metastatic tumor growth and metastasis via targeting metastatic breast cancer by chlorotoxin-modified liposomes. Mol Pharm 11: 3233-3241, 2014.

33. Zucker S and Vacirca J: Role of matrix metalloproteinases (MMPs) in colorectal cancer. Cancer Metastasis Rev 23: 101-117, 2004.

34. Vermeulen SJ, Chen TR, Speleman F, Nollet F, Van Roy FM and Mareel MM: Did the four human cancer cell lines DLD-1, HCT-15, HCT-8 and HRT-18 originate from one and the same patient? Cancer Genet Cytogenet 107: 76-79, 1998.

35. Crowley-Weber CL, Payne CM, Gleason-Guzman M, Watts GS, Futscher B, Waltmire CN, Crowley C, Dvorakova K, Bernstein C, Craven M, et al: Development and molecular characterization of HCT-116 cell lines resistant to the tumor promoter and multiple stress-inducer, deoxycholate. Carcinogenesis 23: 2063-2080, 2002.

36. Cailleau R, Young R, Olivé M and Reeves WJ Jr: Breast tumor cell lines from pleural effusions. J Natl Cancer Inst 53: 661-674, 1974.

37. Franken NA, Rodermond HM, Stap J, Haveman J and van Bree C: Clonogenic assay of cells in vitro. Nat Protoc 1: 2315-2319,2006.

38. Omran MAA: In vitro anticancer effect of scorpion Leiurus quinquestriatus and Egyptian cobra venom on human breast and prostate cancer cell lines. Res J Med Sci 3: 66-86, 2003.

39. Fu YJ, Yin LT, Liang AH, Zhang CF, Wang W, Chai BF, Yang JY and Fan XJ: Therapeutic potential of chlorotoxin-like neurotoxin from the Chinese scorpion for human gliomas. Neurosci Lett 412: 62-67, 2007.

40. Gao F, Li H, Chen YD, Yu XN, Wang R and Chen XL: Upregulation of PTEN involved in scorpion venom-induced apoptosis in a lymphoma cell line. Leuk Lymphoma 50: 633-641, 2009.

41. Islam M, Datta J, Lang JC and Teknos TN: Down regulation of RhoC by microRNA-138 results in de-activation of FAK, Src and Erk1/2 signaling pathway in head and neck squamous cell carcinoma. Oral Oncol 50: 448-456, 2014.

42. Islam M, Sharma S, Kumar B and Teknos TN: Atorvastatin inhibits RhoC function and limits head and neck cancer metastasis. Oral Oncol 49: 778-786, 2013.

43. Schlaepfer DD and Mitra SK: Multiple connections link FAK to cell motility and invasion. Curr Opin Genet Dev 14: 92-101, 2004. 